\title{
Persistence with biologic agents for the treatment of rheumatoid arthritis in Japan
}

\author{
This article was published in the following Dove Press journal: \\ Patient Preference and Adherence \\ 5 August 2016 \\ Number of times this article has been viewed
}

\section{Jörg Mahlich ${ }^{1,2}$ \\ Rosarin Sruamsiri ${ }^{1,3}$}

'Health Economics, Janssen Pharmaceutical KK, Tokyo, Japan; ${ }^{2}$ Düsseldorf Institute for Competition Economics (DICE), University of Düsseldorf, Düsseldorf, Germany; ${ }^{3}$ Center of Pharmaceutical Outcomes Research, Department of Pharmacy Practice, Faculty of Pharmaceutical Sciences, Naresuan University, Phitsanulok, Thailand
Correspondence: Jörg Mahlich Health Economics, Janssen Pharmaceutical KK, 5-2, Nishi-kanda 3-chome Chiyoda-ku, Tokyo, I0I-0065, Japan

Tel $+8|344| \mid 5666$

Fax +8 I 3 44II 5050

Email jmahlich@its.jnj.com
Background: To assess persistence rates of biologic agents for the treatment of rheumatoid arthritis in Japan.

Methods: Based on Japanese claims data of 16,214 patients between 2012 and 2014, 6-, 12-, and 18-month persistence rates of different biologic agents were calculated. Determinants of persistence were assessed by means of a multivariate Cox proportional hazard model controlling for age, sex, and comorbidities. A sensitivity analysis was performed with different definitions of persistence and parametric survival analysis.

Results: Overall persistence rates in Japan are high and reach $86 \%$ after 1 year in the entire sample. The persistence rate for the biologic-naïve subpopulation is above $95 \%$. Persistence is higher for older patients (hazard ratio 0.60 [95\% confidence interval $0.40-0.91]$ for $>75$ years compared to $\leq 60$ years) and lower for patients with a high comorbidity score (hazard ratio 1.33 ; $95 \%$ confidence interval 1.03-1.70 for Charlson Comorbidity Index score $3-5$ compared to $\leq 2$ ). We found a high variation of persistence between different drugs.

Conclusion: Japanese rheumatoid arthritis patients have a high persistence rate of biologic treatments. However, multiple factors affect the persistence rate of Japanese patients, including age, comorbidities, and patient type. Naïve patients tend to have a higher persistence rate than continuing biologic patients.

Keywords: Japan, rheumatoid arthritis, database analysis, persistence, biologics

\section{Background}

Rheumatoid arthritis (RA) is defined as a systemic autoimmune disease characterized by the chronic progression of joint damage. The estimated prevalence of RA is 1.24 million in Japan, which corresponds to $1.0 \%$ of the Japanese population. ${ }^{1}$ The combination of conventional disease-modifying anti-rheumatic drugs such as methotrexate, sulfasalazine, leflunomide, or hydroxychloroquine and the development of biologic agents which are classified according to molecules they target such as tumor necrosis factor inhibitors or, more recently, Janus kinase inhibitor, interleukin-6, interleukin-1, B-cell and T-cell co-stimulation inhibitors have improved the lives of many RA patients as they help to delay or even stop the clinical progression of the disease. ${ }^{2}$ Biologic agents are not only effective with regard to symptom reduction, ${ }^{3}$ their use is also associated with a decrease in mortality. ${ }^{4}$ As poor persistence with biologics can weaken the effectiveness of these medications, a recent stream of research has examined the persistence with biologics and its determinants. Persistence in this context refers to "the duration of time from initiation to discontinuation of therapy" while the related concept of adherence is "the extent to which a patient acts in accordance with the prescribed interval, and dose of a dosing regimen." 5 
Persistence rates were found to vary considerably between different countries and different drugs. A systematic review of 52 studies found persistence rates between $32.0 \%$ and $90.9 \%$ after 1 year. $^{6}$ These rather large variations indicate that institutional and probably cultural factors play a role in explaining the magnitude of persistence rates. Results are therefore contingent on the respective health care delivery system and it is difficult to compare the findings between countries.

Most studies are either from Europe ${ }^{7-16}$ or North America, ${ }^{17-23}$ while studies in Asian populations are scarce. Apart from two Korean studies, ${ }^{24,25}$ one Japanese prospective cohort study was identified that analyzed patients who started biologic treatment with infliximab, etanercept, or tocilizumab. ${ }^{26}$ The authors found significant differences in demography, clinical status, comorbidities, and usage of concomitant drugs among the three drugs. Compared with etanercept, the use of infliximab (hazard ratio [HR] 1.69) and tocilizumab (HR 1.98) was significantly associated with a higher risk of discontinuation of biological agents due to adverse events. However, the data cutoff in this analysis was April 2011. For this reason, it is worthwhile to have a fresh look on persistence rates in a Japanese context because since these previous studies new biologic agents have been introduced to the Japanese market. To date, seven biological agents have been approved in Japan, namely, infliximab (2002), etanercept (2005), tocilizumab and adalimumab (both in 2008), abatacept (2010), golimumab (2011), and certolizumab pegol (2013). The current study has included more drugs compared to previous studies, and to the best of our knowledge, it is also the first Japanese database analysis on this topic.

\section{Methods}

\section{Data source}

We utilized commercially available hospital claims data from Medical Data Vision Co., Ltd. This is an administrative database for inpatients and outpatients and includes around $4,400,000$ patients. This number represents around $3 \%$ of the total Japanese population. The age distribution in the database is $13.5 \% 0-14$ years old, 52.4\% 15-64 years old, and 34.1\% 65 years old and resembles that of the general population. ${ }^{27}$ The data were obtained from hospital electronic information systems derived from 147 acute-phase hospitals throughout Japan. The hospitals operate 40,000 beds and are registered as Diagnosis Procedure Combination (DPC) hospitals. The DPC is a diagnosis-related group-like flat fee system that was introduced in 2003 for big hospitals in Japan. ${ }^{28}$ The time span of our analysis was from April 2012 to March 2014.
The data in this study were de-identified by the database provider; therefore, no informed consent was necessary. The study was in line with the guidelines of Johnson \& Johnson and approved by the Janssen approval committee.

\section{Study population and study design}

The identification of the study population was based on the International Classification of Diseases, 10th revision (ICD-10). RA patients were diagnosed as ICD-10: M05.x, M06.0, M06.2-M06.9. Patients were required to have at least two diagnoses included. The index date was defined as the first claim for a biologic medication. All patients had to be available for a 12-month follow-up period after the index date and a 3-month washout period before the index date. Children below 18 years and patients with Crohn's disease, ankylosing spondylitis, juvenile arthritis, psoriasis, ulcerative colitis, and/or Behçet's disease were excluded because some biologics have an additional indication in these diseases. Following the approach of Neubauer et al (2014) ${ }^{9}$ patients were categorized as "biologic-naïve" or "biologiccontinuing": naïve patients were patients who had no biologic prescription during the first 3 months of their observation period. Continuing patients were defined as patients with at least one biologic prescription at their index date. Additionally, naïve patients were also required to receive at least two disease-modifying antirheumatic drug prescriptions before the index date. As patient numbers for certolizumab pegol were extremely small (two biologic-naïve and six continuing patients), we removed certolizumab pegol patients from the analysis.

Comorbidities were measured by means of the Charlson Comorbidity Index (CCI). The ICD-10 coding algorithms for Charlson comorbidities were made available by Quan et al. ${ }^{29}$ The CCI includes 19 comorbidities (myocardial infarction, congestive heart failure, peripheral vascular disease, cerebrovascular disease, dementia, chronic pulmonary disease, rheumatic disease, peptic ulcer disease, mild liver disease, diabetes without chronic complication, diabetes with chronic complication, hemiplegia or paraplegia, renal disease, tumors without metastasis, lymphoma, leukemia, moderate or severe liver disease, metastatic solid tumors, and AIDS/HIV) and assigns a weight between 1 and 6 for each of those comorbidities. Higher CCI indicates a greater morbidity of the patient.

\section{Calculation of persistence rates}

The persistence rate was defined as the time from treatment initiation (index date) until discontinuation of the index 


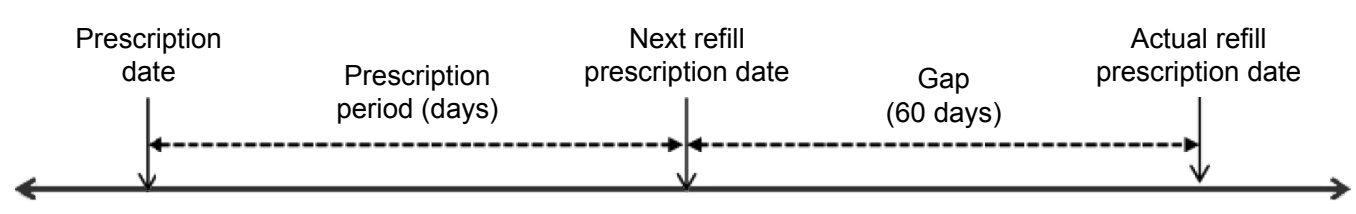

Medication discontinuation $=$ Actual refill prescription date $>$ prescription period +60

Figure I Definition of persistence in base case (60 days medication gap).

biologic agent. We defined the index date as the first biologic prescription in the database. Patients were defined as discontinued index biologic treatment if either of the following occurred first: 1) if a gap in the days' supply of the index biologic agent exceeding the medication gap was encountered, or 2) if the patient switched from the index biologic agent to other treatments during the follow-up. In the base case, we used a medication gap of 60 days to define medication discontinuation (Figure 1). This definition of persistence is consistent with other claims data study days in $\mathrm{RA}^{9,30}$ and other indications. ${ }^{31}$ To estimate the days' supply of index medication, we referred to the standard recommended dose of RA treatment ${ }^{32}$ for each biologic agent multiplied by the number of biologic agents per prescription.

\section{Statistical analysis}

Descriptive statistics were used for demographic characteristics and treatment persistence with biologic agents. Chi-square and Wilcoxon rank sum tests were used to assess the difference between biologic-naïve and -continuing patients. A Kaplan-Meier analysis was used to calculate the persistence of biologic treatment. Differences in persistence were tested for significance using the log rank and Wilcoxon tests. A $P$-value of 0.05 (two-sided) was considered statistically significant. To analyze the determinants of persistence, we employed a Cox proportional hazard model as the base case with age, sex, CCI, and the medication as independent variables. We examined the determinants of persistence for both naïve and continuing RA patients. Coefficients were stated as HRs. The analysis was undertaken using STATA (StataCorp LP, College Station, TX, USA).

\section{Sensitivity analysis}

To assess how sensitive the results were with regard to the choice of the gap definition, we also reported results based on alternative gap definitions, namely, 30 and 120 days. Both are common thresholds within RA and, in general, ${ }^{8,33}$ some studies even used gaps up to 180 days to define persistence. ${ }^{34}$ In addition, we also used a parametric model to complement the results of the semiparametric Cox model. Because Cox models assume that hazards are proportional, they are not suitable when hazards are disproportional. For this reason, we tested the robustness of the results by employing a parametric estimator (Weibull probability distribution) where all parts of the model need to be specified.

\section{Results \\ Study population}

According to the inclusion criteria, 2,265 biologic-experienced patients and 272 biologic-naïve patients were identified (see Figure 2 for a description of the study population).

Table 1 provides an overview of the study population stratified by biologic-naïve and -continuing patients. The average age was slightly below 60 years without significant differences between the two groups. The majority of the patients were female and biologic-naïve patients were more morbid than those who were already on treatment during the baseline period. Greater numbers of ulcer patients were identified in continuing patients while the prevalence of chronic liver diseases was higher in naïve patients. Continuing patients were mainly on etanercept, while infliximab was the most prescribed drug in naïve RA patients.

\section{Persistence}

Figure 3 presents the Kaplan-Meier curves for the overall sample, for biologic-naïve and -continuing patients. The persistence was high for the biologic-naïve population. One-year persistence rates ranged between $85.3 \%$ (95\% confidence interval [CI]: 83.8\%-86.7\%) for continuing patients and $95.6 \%$ (95\% CI: 92.5\%-97.5\%) for naïve patients. The difference was statistically significant.

Figure 4 shows Kaplan-Meier Curves for the different biologic drugs, and Table 2 reports the associated persistence rates.

Among naïve patients, 1-year persistence rates varied from $89.6 \%$ (95\% CI: $76.7 \%-95.5 \%$ ) for etanercept to $100 \%$ for golimumab. Continuing patients had persistence rates between 78.9\% (95\% CI: 76.0\%-81.5\%) for etanercept and 96.0\% (95\% CI: 90.7\%-98.3\%) for abatacept. 


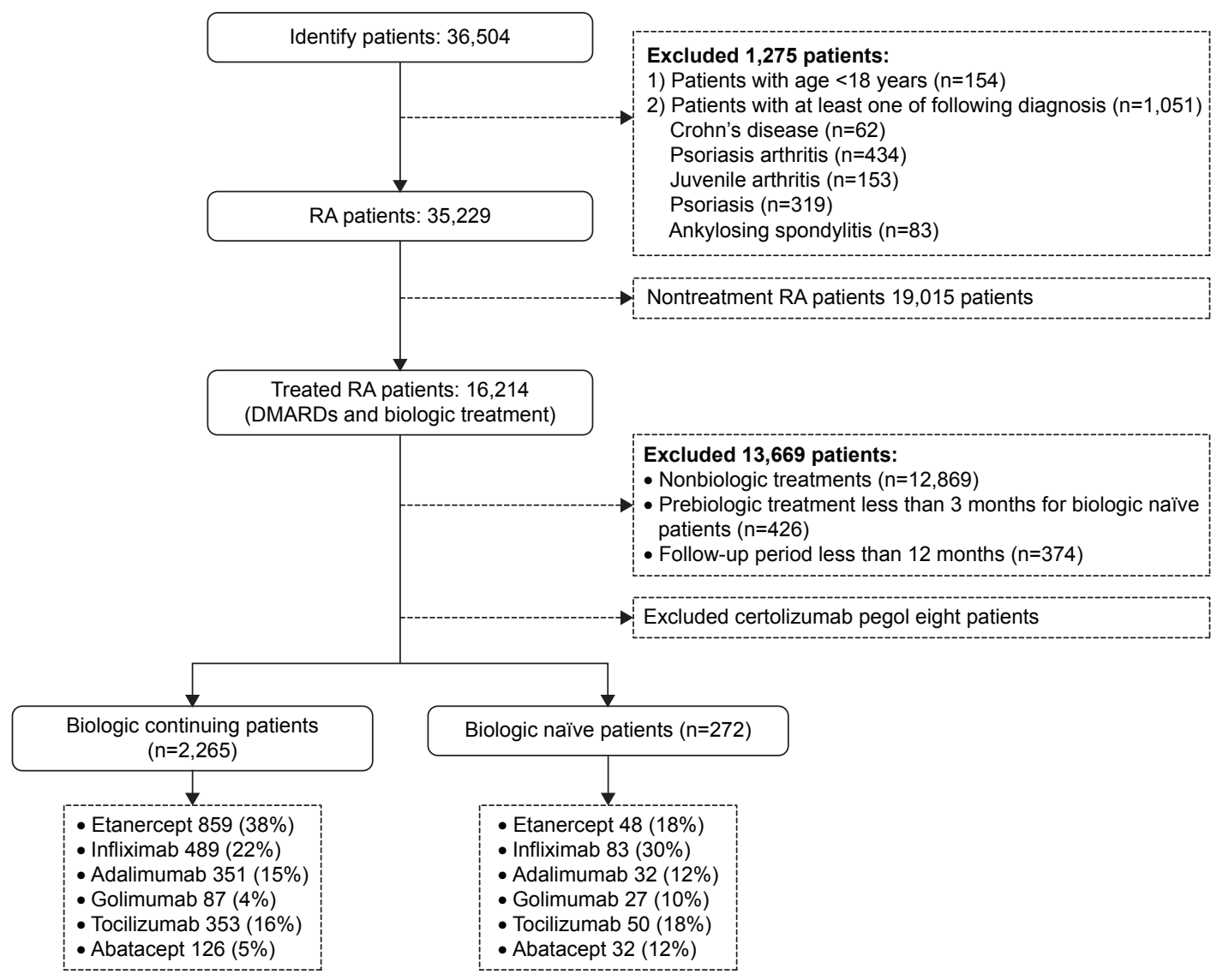

Figure 2 Study population.

Note: Data are presented as $\mathrm{n}(\%)$ unless indicated.

Abbreviations: DMARDs, disease-modifying antirheumatic drugs; RA, rheumatoid arthritis.

The tests for significance are shown in Table 3. Because the Wilcoxon test results are very similar to the log rank tests, we only reported the log rank test results. For naïve patients, the following significant relationship held with regard to persistence: infliximab > etanercept. All other drugs did not differ significantly from each other.

To explain the differences in persistence, we estimated a Cox regression (Table 4). Although higher age did not influence persistence in naïve patients, it was a significant driver in the continuing patient population. Patients aged 75 and above had lower hazards of treatment discontinuation or, alternatively, were more persistent compared to the reference group (younger than 60 years of age). No differences were observed with regard to sex. In the naïve population, the CCI also did not have an impact on persistence. However, a higher comorbidity index was associated with a higher hazard of treatment discontinuation in the continuing population. After controlling for age, sex, and comorbidities, the results suggested lower hazards of treatment discontinuation in the continuing population for infliximab, golimumab, tocilizumab, and abatacept compared to the reference case, etanercept.

\section{Sensitivity analysis}

In the sensitivity analysis, alternative gap definitions were applied, namely, 30 and 120 days, instead of the 90 days in the baseline analysis. Table 5 reports the results of the sensitivity analysis. Applying a 30 days gap definition, 12 month persistence rates in the naïve population were highest for abatacept (93.7\% [95\% CI: 77.2\%-98.4\%]) and golimumab (96.3\% [95\% CI: 76.5\%-99.5\%]) and lowest for etanercept (68.8\% [95\% CI: 53.6\%-79.8\%]). With a 120 days gap definition that allowed for a 3-month treatment break, most drugs reached a $100 \%$ persistence rate.

The results of the parametric regression are shown in Table 6. The results confirm lower hazards of treatment discontinuation for older patients, and a higher hazard for patients with a higher CCI score. The drug specific results were comparable. The shape of parameter $p$ of the Weibull distribution was close to one in the overall population 
Table I Characteristics of biologic-naïve and -continuing patients

\begin{tabular}{|c|c|c|c|}
\hline Characteristics & Biologic-continuing patients, n (\%) & Biologic-naïve patients, n (\%) & $P$-value \\
\hline RA patients & 2,265 & 272 & \\
\hline Age (mean \pm SD) & $59.90 \pm 13.25$ & $58.69 \pm 14.59$ & 0.1575 \\
\hline$\leq 60$ years & $1,018(45 \%)$ & $129(47 \%)$ & \\
\hline $61-75$ years & $\mathrm{I}, 036(46 \%)$ & $116(43 \%)$ & \\
\hline$>75$ years & $211(9 \%)$ & $27(10 \%)$ & \\
\hline Sex & & & 0.236 \\
\hline Male & $463(20 \%)$ & $64(23 \%)$ & \\
\hline Female & $\mathrm{I}, 802(80 \%)$ & $208(77 \%)$ & \\
\hline $\mathrm{CCl}$ score (mean $\pm \mathrm{SD})$ & $3.60 \pm 2.27$ & $4.22 \pm 2.89$ & $<0.001$ \\
\hline$\leq 2$ & $855(38 \%)$ & 81 (30\%) & \\
\hline $3-5$ & $\mathrm{I}, 023(45 \%)$ & $126(46 \%)$ & \\
\hline$>5$ & $387(17 \%)$ & $65(24 \%)$ & \\
\hline \multicolumn{4}{|l|}{ Comorbidity } \\
\hline Myocardial infarction & $90(4 \%)$ & $9(3 \%)$ & 0.593 \\
\hline Congestive heart failure & $629(28 \%)$ & $88(32 \%)$ & 0.113 \\
\hline Peripheral vascular disease & $225(10 \%)$ & $36(13 \%)$ & 0.090 \\
\hline Cerebrovascular disease & $279(12 \%)$ & $43(16 \%)$ & 0.102 \\
\hline Dementia & $33(1 \%)$ & $5(2 \%)$ & 0.625 \\
\hline Chronic lung disease & $598(26 \%)$ & $84(31 \%)$ & 0.115 \\
\hline Ulcer & $1,013(45 \%)$ & $104(38 \%)$ & 0.042 \\
\hline Chronic liver disease & $886(39 \%)$ & $154(57 \%)$ & $<0.001$ \\
\hline Diabetes & $2,265(7 \%)$ & $19(7 \%)$ & 0.777 \\
\hline Blood disorder disease & $8(0 \%)$ & I (0\%) & 0.970 \\
\hline Moderate or severe kidney disease & $96(4 \%)$ & $19(7 \%)$ & 0.040 \\
\hline Diabetes with end organ damage & $83(4 \%)$ & $15(6 \%)$ & 0.135 \\
\hline Moderate or severe liver disease & $8(0 \%)$ & $\mathrm{I}(0 \%)$ & 0.970 \\
\hline Tumor and cancer & $250(11 \%)$ & $23(8 \%)$ & 0.085 \\
\hline
\end{tabular}

Abbreviations: $\mathrm{CCl}$, Charlson Comorbidity Index; RA, rheumatoid arthritis; SD, standard deviation.

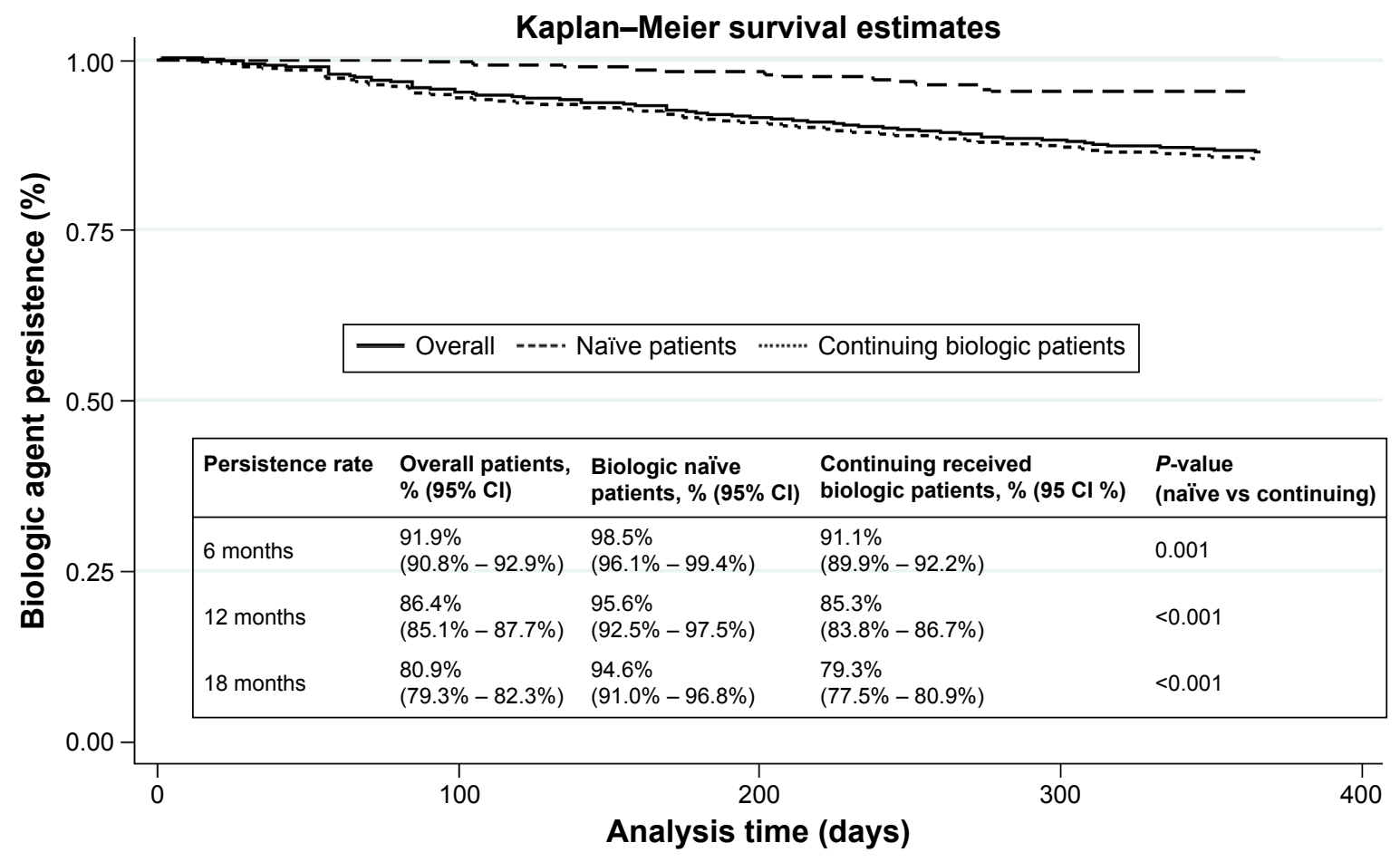

Figure 3 Kaplan-Meier curves for biologic agent patients. 


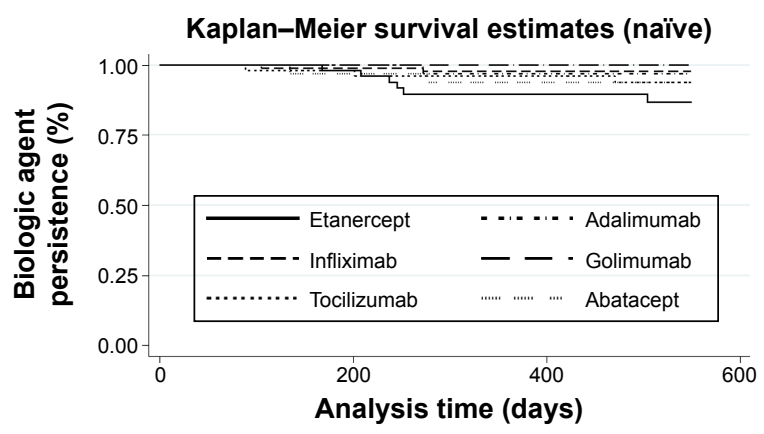

Figure 4 Kaplan-Meier curves of naïve biologic agent patients.

indicating an almost constant hazard over time. However, the HR of naïve patients might increase over time.

\section{Discussion}

\section{Persistence rates}

Our analysis adds more insights to the persistence of biologic agents, which were not reported in previous Japanese studies. ${ }^{24}$ Compared to international persistence studies, the persistence observed for Japan appears to be much higher. The baseline rate of $95.3 \%$ for naïve patients is even higher than the highest rate reported in a systematic review of 52 studies. ${ }^{5}$ In a German claims data study, ${ }^{9}$ which is most similar to ours in terms of study design, the following 1-year persistence rates were reported for naïve patients: $51.0 \%$ for etanercept, $50.0 \%$ for adalimumab, and $48.0 \%$ for infliximab. Our results using data from Japan indicated a much better persistence: $89.6 \%$ for etanercept, $96.9 \%$ for adalimumab, and $97.6 \%$ for infliximab. Clinical studies have confirmed that persistence rates in Japanese clinical practice are relatively high. One noncomparative retrospective study reported a 1-year persistence rate of infliximab of $75.6 \%{ }^{35}$ Postmarketing surveillance data of etanercept suggested a persistence rate of $82.4 \%$ after 6 months. ${ }^{36}$ It is unlikely that the extremely high persistent rates we observed in our study were due to a selection bias of our study population. As we only included patients with a follow-up period of 12 months or more, a selection bias would be present if patients who were not included in the study due to loss to follow-up were missing not at random but because of relevant reasons related to their biologic treatment. In our case, 347 patients who started a biologic treatment were lost to follow-up, which corresponds to a ratio of $12.8 \%$. In evidence-based medicine, a loss of follow-up below $20 \%$ is usually considered acceptable even for high evidence level studies. ${ }^{37}$

Conversely, the persistence rates we found for Japan might even be biased downwards if Japanese patients use lower dosages due to weight differences. In that case, the medication supply would be longer for any prescribed drug. This implies that patients who do not refill their prescription might still be under treatment, and our analysis would classify them as being nonpersistent.

The reason we reported persistence rates separately for biologic-naïve and -continuing patients is that continuing patients are subject to a number of potential biases. First, continuing patients with a successful treatment history with a biologic might constitute a positive selection of the underlying population, which would give rise to a positive selection bias. Second, the opposite might also occur. If a natural rate of treatment failure is assumed, those patients who are already on treatment for a long time have a higher propensity of discontinuing their medication. As we did not observe the starting date for the treatment-continuing subpopulation, we

Table 2 Persistence rates and $95 \% \mathrm{Cls}$

\begin{tabular}{|c|c|c|c|c|c|c|c|c|c|}
\hline \multirow{2}{*}{$\begin{array}{l}\text { Biologic } \\
\text { agents }\end{array}$} & \multicolumn{3}{|c|}{ Overall, \% (95\% Cl) } & \multicolumn{3}{|c|}{ Biologic-naïve patients, $\%(95 \% \mathrm{Cl})$} & \multicolumn{3}{|c|}{ Biologic-continuing patients, $\%(95 \% \mathrm{Cl})$} \\
\hline & 6 months & 12 months & 18 months & 6 months & 12 months & 18 months & 6 months & 12 months & 18 months \\
\hline Etanercept & $\begin{array}{l}87.5 \\
(85.2-89.5)\end{array}$ & $\begin{array}{l}79.5 \\
(76.7-81.9)\end{array}$ & $\begin{array}{l}70.6 \\
(67.5-73.5)\end{array}$ & $\begin{array}{l}97.9 \\
(86.1-99.7)\end{array}$ & $\begin{array}{l}89.6 \\
(76.7-95.5)\end{array}$ & $\begin{array}{l}86.6 \\
(72.3-93.8)\end{array}$ & $\begin{array}{l}86.9 \\
(84.5-89.0)\end{array}$ & $\begin{array}{l}78.9 \\
(76.0-81.5)\end{array}$ & $\begin{array}{l}69.8 \\
(66.6-72.8)\end{array}$ \\
\hline Adalimumab & $\begin{array}{l}91.1 \\
(87.8-93.6)\end{array}$ & $\begin{array}{l}84.3 \\
(80.3-87.6)\end{array}$ & $\begin{array}{l}78.7 \\
(74.2-82.6)\end{array}$ & 100 & $\begin{array}{l}96.9 \\
(79.8-99.6)\end{array}$ & $\begin{array}{l}96.9 \\
(79.8-99.6)\end{array}$ & $\begin{array}{l}90.3 \\
(86.7-92.9)\end{array}$ & $\begin{array}{l}83.2 \\
(78.8-86.7)\end{array}$ & $\begin{array}{l}77.2 \\
(72.4-8 \mid .2)\end{array}$ \\
\hline Infliximab & $\begin{array}{l}95.8 \\
(93.8-97.2)\end{array}$ & $\begin{array}{l}93.5 \\
(91.2-95.3)\end{array}$ & $\begin{array}{l}91.5 \\
(88.9-93.6)\end{array}$ & $\begin{array}{l}98.8 \\
(91.8-99.8)\end{array}$ & $\begin{array}{l}97.6 \\
(90.7-99.4)\end{array}$ & $\begin{array}{l}97.6 \\
(90.7-99.4)\end{array}$ & $\begin{array}{l}95.3 \\
(93.0-96.8)\end{array}$ & $\begin{array}{l}92.8 \\
(90.2-94.8)\end{array}$ & $\begin{array}{l}90.5 \\
(87.5-92.8)\end{array}$ \\
\hline Golimumab & $\begin{array}{l}93.9 \\
(87.6-97.0)\end{array}$ & $\begin{array}{l}91.2 \\
(84.3-95.2)\end{array}$ & $\begin{array}{l}85.6 \\
(77.5-90.9)\end{array}$ & 100 & 100 & 100 & $\begin{array}{l}91.9 \\
(83.7-96.1)\end{array}$ & $\begin{array}{l}88.5 \\
(79.7-93.6)\end{array}$ & $\begin{array}{l}81.5 \\
(71.6-88.2)\end{array}$ \\
\hline Tocilizumab & $\begin{array}{l}94.5 \\
(91.8-96.4)\end{array}$ & $\begin{array}{l}89.1 \\
(85.6-91.8)\end{array}$ & $\begin{array}{l}84.2 \\
(80.2-87.4)\end{array}$ & $\begin{array}{l}98.0 \\
(86.6-99.7)\end{array}$ & $\begin{array}{l}96.0 \\
(84.9-98.9)\end{array}$ & $\begin{array}{l}93.7 \\
(81.7-97.9)\end{array}$ & $\begin{array}{l}94.5 \\
(91.0-96.1)\end{array}$ & $\begin{array}{l}88.1 \\
(84.2-91.1)\end{array}$ & $\begin{array}{l}82.8 \\
(78.5-86.4)\end{array}$ \\
\hline Abatacept & $\begin{array}{l}96.8 \\
(92.6-98.7)\end{array}$ & $\begin{array}{l}95.6 \\
(90.9-97.9)\end{array}$ & $\begin{array}{l}94.9 \\
(90.0-97.4)\end{array}$ & $\begin{array}{l}96.8 \\
(79.8-99.6)\end{array}$ & $\begin{array}{l}93.7 \\
(77.2-98.4)\end{array}$ & $\begin{array}{l}93.7 \\
(77.2-98.4)\end{array}$ & $\begin{array}{l}96.8 \\
(91.8-98.8)\end{array}$ & $\begin{array}{l}96.0 \\
(90.7-98.3)\end{array}$ & $\begin{array}{l}95.2 \\
(89.6-97.8)\end{array}$ \\
\hline
\end{tabular}

Abbreviation: $\mathrm{Cl}$, confidence interval. 
Table $3 P$-values of log rank tests

\begin{tabular}{|c|c|c|c|c|c|c|c|c|c|c|c|c|c|c|c|}
\hline \multirow{2}{*}{$\begin{array}{l}\text { Biologic } \\
\text { agents }\end{array}$} & \multicolumn{5}{|c|}{ Overall } & \multicolumn{5}{|c|}{ Biologic-naïve patients } & \multicolumn{5}{|c|}{ Biologic-continuing patients } \\
\hline & $\overline{A D L}$ & IFX & GOL & TCZ & ABT & $\overline{A D L}$ & IFX & GOL & TCZ & ABT & ADL & IFX & GOL & TCZ & ABT \\
\hline ETN & 0.007 & $<0.001$ & 0.011 & $<0.001$ & $<0.001$ & 0.142 & 0.018 & 0.068 & 0.258 & 0.388 & 0.012 & $<0.001$ & 0.030 & $<0.001$ & $<0.001$ \\
\hline ADL & - & $<0.001$ & 0.340 & 0.063 & $<0.001$ & - & 0.836 & 0.358 & 0.573 & 0.557 & - & $<0.001$ & 0.398 & 0.082 & $<0.001$ \\
\hline IFX & - & - & 0.024 & $<0.001$ & 0.203 & - & - & 0.418 & 0.297 & 0.320 & - & - & 0.013 & 0.001 & 0.102 \\
\hline GOL & - & - & - & 0.999 & 0.008 & - & - & - & 0.226 & 0.190 & - & - & - & 0.777 & 0.002 \\
\hline TCZ & - & - & - & - & 0.001 & - & - & - & - & 0.925 & - & - & - & - & 0.001 \\
\hline
\end{tabular}

Note: The numbers show the result of our comparison between one biologic vs another biologic agent.

Abbreviations: ABT, abatacept; ADL, adalimumab; ETN, etanercept; GOL, golimumab; IFX, infliximab; TCZ, tocilizumab.

cannot control for this potential bias in our analysis. For this reason, the results of the continuing subpopulation need to be interpreted with caution.

Another potential bias that is common in database analysis and which affects both the continuing and the naïve population is the so-called channeling bias. A channeling bias is defined as an "allocation bias, where drugs with similar therapeutic indications are prescribed to groups of patients with prognostic differences." ${ }^{38}$ Claimed advantages of a new drug may channel it to patients with special preexisting morbidity, with the consequence that disease states can be incorrectly attributed to use of the drug. ${ }^{38}$ If newer drugs are used in patients who are more morbid or who have failed previous treatments, and morbidity in turn is correlated to treatment discontinuation, drugs that were introduced only recently would be subject to a negative selection bias.

The sensitivity analysis suggested that persistence rates remained high and were relatively robust to variations in the gap definitions employed. Other studies confirmed a generally high persistence and adherence of Japanese patients compared with Western patients, and have attributed this to cultural beliefs and the authority of physicians in Japan. ${ }^{39}$ The large variations in persistence between different countries with the same drugs underline the necessity of collecting local real-world data that reflect both differences in the health care systems and culture in general.

Table 4 Cox regression

\begin{tabular}{|c|c|c|c|}
\hline \multirow[t]{2}{*}{ Patient characteristics } & \multicolumn{3}{|c|}{ Hazard ratio ( $95 \%$ confidence interval) } \\
\hline & $\begin{array}{l}\text { Overall patients } \\
(n=2,537)\end{array}$ & $\begin{array}{l}\text { Biologic-naïve patients } \\
(\mathrm{n}=\mathbf{2 7 2})\end{array}$ & $\begin{array}{l}\text { Biologic-continuing patients } \\
(n=2,265)\end{array}$ \\
\hline \multicolumn{4}{|l|}{ Age } \\
\hline$\leq 60$ years & Reference & Reference & Reference \\
\hline $61-75$ years & $0.88(0.67-1.05)$ & $1.05(0.29-3.80)$ & $0.83(0.66-1.04)$ \\
\hline$>75$ years & $0.60(0.40-0.91)$ & $1.83(0.34-9.95)$ & $0.56(0.37-0.86)$ \\
\hline \multicolumn{4}{|l|}{ Sex } \\
\hline Male & Reference & Reference & Reference \\
\hline Female & $\mathrm{I} .03(0.79-1.34)$ & $0.49(0.14-1.73)$ & $1.05(0.80-1.38)$ \\
\hline \multicolumn{4}{|l|}{ CCI score } \\
\hline$\leq 2$ & Reference & Reference & Reference \\
\hline $3-5$ & $1.33(1.03-1.70)$ & $5.29(0.94-4 I .2 I)$ & $1.26(0.98-1.6 I)$ \\
\hline$>5$ & $1.89(1.40-2.57)$ & $1.87 \times 10^{9}$ & $1.93(1.42-2.62)$ \\
\hline \multicolumn{4}{|l|}{ Biologic agent } \\
\hline Etanercept & Reference & Reference & Reference \\
\hline Adalimumab & $0.76(0.57-1.02)$ & $0.30(0.03-2.68)$ & $0.78(0.58-1.05)$ \\
\hline Infliximab & $0.32(0.22-0.45)$ & $0.23(0.04-1.23)$ & $0.32(0.22-0.46)$ \\
\hline Golimumab & $0.46(0.24-0.87)$ & $9.59 \times 10^{-19}$ & $0.52(0.27-0.97)$ \\
\hline Tocilizumab & $0.5 \mathrm{I}(0.37-0.7 \mathrm{I})$ & $0.29(0.05-1.53)$ & $0.52(0.37-0.72)$ \\
\hline Abatacept & $0.20(0.10-0.44)$ & $0.49(0.09-2.67)$ & $0.16(0.07-0.39)$ \\
\hline \multicolumn{4}{|l|}{ Naïve } \\
\hline Naïve patients & Reference & & \\
\hline \multirow[t]{3}{*}{ Continuing biologic patients } & $3.01(1.69-5.38)$ & & \\
\hline & $\operatorname{LR} \chi^{2}(12)=119.90$ & $\operatorname{LR} \chi^{2}(12)=18.62$ & $\operatorname{LR} \chi^{2}(12)=92.01$ \\
\hline & Prob $>\chi^{2}=0.0000$ & Prob $>\chi^{2}=0.0286$ & Prob $>\chi^{2}=0.0000$ \\
\hline
\end{tabular}

Abbreviations: $\mathrm{CCl}$, Charlson Comorbidity Index; LR $\left(\chi^{2}\right)$, likelihood ratio chi-square; Prob, probability. 
Table 5 Persistence rates (\%) and 95\% Cls of biologic-naïve patients for 30- and 120-day gap definition

\begin{tabular}{|c|c|c|c|c|c|c|c|c|c|}
\hline \multirow{2}{*}{$\begin{array}{l}\text { Biologic } \\
\text { agents }\end{array}$} & \multicolumn{3}{|c|}{ Overall, \% (95\% Cl) } & \multicolumn{3}{|c|}{ Biologic-naïve patients, \% (95\% Cl) } & \multicolumn{3}{|c|}{ Biologic-continuing patients, $\%(95 \% \mathrm{Cl})$} \\
\hline & 6 months & 12 months & 18 months & 6 months & 12 months & 18 months & 6 months & 12 months & 18 months \\
\hline \multicolumn{10}{|l|}{ 30-day gap } \\
\hline \multirow[t]{2}{*}{ Etanercept } & 68.2 & 55.7 & 46.1 & 87.5 & 68.8 & 58.3 & 67.2 & 54.9 & 45.5 \\
\hline & $(65.1-7 \mid .2)$ & $(52.4-58.8)$ & $(42.8-49.3)$ & $(74.3-94.2)$ & $(53.6-79.8)$ & $(42.4-71.3)$ & $(63.9-70.2)$ & $(51.6-58.2)$ & $(42.1-48.8)$ \\
\hline \multirow[t]{2}{*}{ Adalimumab } & 83.5 & 71.3 & 65.2 & 90.6 & 81.2 & 72.4 & 82.9 & 70.4 & 64.4 \\
\hline & $(79.4-86.9)$ & $(66.5-75.5)$ & $(60.1-69.7)$ & $(73.7-96.9)$ & $(63.0-91.1)$ & $(51.6-85.4)$ & $(78.5-86.5)$ & $(65.3-74.8)$ & $(59.1-69.2)$ \\
\hline \multirow[t]{2}{*}{ Infliximab } & 92.0 & 86.0 & 83.3 & 95.2 & 91.6 & 91.6 & 91.4 & 85.1 & 81.9 \\
\hline & (89.4-94.9) & $(82.9-88.6)$ & $(79.9-86.1)$ & (87.7-98.2) & $(83.1-95.9)$ & $(83.1-95.9)$ & $(88.6-93.6)$ & $(81.6-87.9)$ & $(78.2-85.0)$ \\
\hline \multirow[t]{2}{*}{ Golimumab } & 92.1 & 86.8 & 80.3 & 100 & 96.3 & 90.6 & 89.7 & 83.9 & 76.9 \\
\hline & $(85.4-95.8)$ & (79.I-91.8) & $(71.6-86.6)$ & & (76.5-99.5) & $(66.5-97.7)$ & $(8 I . I-94.5)$ & $(74.3-90.1)$ & $(66.6-84.5)$ \\
\hline \multirow[t]{2}{*}{ Tocilizumab } & 57.3 & 45.4 & 34.4 & 82.0 & 66.0 & 46.6 & 53.8 & 42.5 & 32.6 \\
\hline & $(52.3-62.0)$ & $(40.5-50.2)$ & $(29.7-39.1)$ & $(68.3-90.2)$ & $(5 \mathrm{I} . \mathrm{I}-77.3)$ & $(31.5-60.4)$ & $(48.5-58.9)$ & $(37.3-47.6)$ & $(27.7-37.5)$ \\
\hline \multirow[t]{2}{*}{ Abatacept } & 91.7 & 88.6 & 85.7 & 96.8 & 93.7 & 89.7 & 90.5 & 87.3 & 84.7 \\
\hline & $(86.2-95.1)$ & $(82.5-92.6)$ & $(79.2-90.4)$ & (79.8-99.6) & (77.2-98.4) & $(71.9-96.6)$ & $(83.8-94.5)$ & $(80.1-92.0)$ & $(77.1-89.9)$ \\
\hline \multicolumn{10}{|l|}{ |20-day gap } \\
\hline \multirow[t]{2}{*}{ Etanercept } & 92.6 & 88.3 & 82.4 & 100 & 97.9 & 94.9 & 92.2 & 87.8 & 81.7 \\
\hline & $(90.7-94.1)$ & (86.0-90.2) & $(79.7-84.7)$ & & (86.I-99.7) & $(80.9-98.7)$ & (90.2-93.8) & (85.4-89.8) & $(78.9-84.2)$ \\
\hline \multirow[t]{2}{*}{ Adalimumab } & 94.5 & 90.1 & 86.4 & 100 & 100 & 100 & 94.0 & 89.2 & 85.3 \\
\hline & (91.7-96.4) & $(86.6-92.7)$ & $(82.6-89.5)$ & & & & $(91.0-96.1)$ & $(85.4-92.0)$ & $(81.1-88.6)$ \\
\hline \multirow[t]{2}{*}{ Infliximab } & 96.1 & 94.2 & 92.8 & 98.8 & 97.6 & 97.6 & 95.7 & 93.7 & 91.9 \\
\hline & $(94.2-97.4)$ & $(92.0-95.9)$ & $(90.3-94.6)$ & (91.7-99.8) & (90.7-99.4) & $(90.7-99.4)$ & $(93.5-97.2)$ & (9l.I-95.5) & $(89.2-94.1)$ \\
\hline \multirow[t]{2}{*}{ Golimumab } & 93.9 & 91.2 & 85.6 & 100 & 100 & 100 & 92.0 & 88.5 & 81.5 \\
\hline & $(87.6-97.0)$ & (84.3-95.2) & $(77.5-90.9)$ & & & & $(83.9-96.1)$ & (79.7-93.6) & (71.6-88.2) \\
\hline \multirow[t]{2}{*}{ Tocilizumab } & 97.3 & 93.8 & 91.5 & 100 & 98.0 & 98.0 & 100 & 100 & 100 \\
\hline & $(95.1-98.5)$ & (91.0-95.8) & $(88.3-93.8)$ & & (86.6-99.7) & $(86.6-99.7)$ & & & \\
\hline \multirow[t]{2}{*}{ Abatacept } & 100 & 100 & 99.3 & 100 & 100 & 100 & 96.9 & 93.2 & 90.6 \\
\hline & & & $(95.3-99.9)$ & & & & $(94.4-98.3)$ & (90.0-95.4) & $(87.0-93.2)$ \\
\hline
\end{tabular}

Abbreviation: $\mathrm{Cl}$, confidence interval.

Table 6 Parametric regression (Weibull distribution with 60 days gap definition)

\begin{tabular}{|c|c|c|c|}
\hline \multirow[t]{2}{*}{ Patient characteristics } & \multicolumn{3}{|c|}{ Hazard ratio ( $95 \%$ confidence interval) } \\
\hline & $\begin{array}{l}\text { Overall patients } \\
(n=2,537)\end{array}$ & $\begin{array}{l}\text { Biologic-naïve patients } \\
(n=272)\end{array}$ & $\begin{array}{l}\text { Biologic-continuing patients } \\
(n=2,265)\end{array}$ \\
\hline \multicolumn{4}{|l|}{$\overline{\text { Age }}$} \\
\hline$\leq 60$ years & Reference & Reference & Reference \\
\hline $6 I-75$ years & $0.84(0.67-1.05)$ & $1.04(0.29-3.76)$ & $0.83(0.66-1.04)$ \\
\hline$>75$ years & $0.60(0.40-0.91)$ & $1.89(0.35-10.32)$ & $0.56(0.37-0.86)$ \\
\hline \multicolumn{4}{|l|}{ Sex } \\
\hline Male & Reference & Reference & Reference \\
\hline Female & $1.03(0.79-1.34)$ & $0.48(0.13-1.70)$ & $1.05(0.80-1.38)$ \\
\hline \multicolumn{4}{|l|}{ CCI score } \\
\hline$\leq 2$ & Reference & Reference & Reference \\
\hline $3-5$ & $1.33(1.03-1.70)$ & $25.22(0.82-25 I .4 I)$ & $1.26(0.98-1.62)$ \\
\hline$>5$ & $1.90(1.40-2.57)$ & $71.82(-23.45$ to 962.12$)$ & $1.93(1.42-2.63)$ \\
\hline \multicolumn{4}{|l|}{ Biologic agent } \\
\hline Etanercept & Reference & Reference & Reference \\
\hline Adalimumab & $0.76(0.57-1.02)$ & $0.29(0.03-2.65)$ & $0.78(0.58-1.05)$ \\
\hline Infliximab & $0.31(0.22-0.45)$ & $0.22(0.04-\mid .2 I)$ & $0.32(0.22-0.45)$ \\
\hline Golimumab & $0.46(0.24-0.87)$ & $1.59 \times 10^{-8}$ & $0.5 \mathrm{I}(0.27-0.97)$ \\
\hline Tocilizumab & $0.5 I(0.36-0.7 I)$ & $0.28(0.05-1.48)$ & $0.51(0.37-0.72)$ \\
\hline Abatacept & $0.20(0.09-0.43)$ & $0.48(0.09-2.61)$ & $0.16(0.07-0.39)$ \\
\hline \multicolumn{4}{|l|}{ Naïve } \\
\hline Naïve patients & Reference & NA & NA \\
\hline Continuing biologic patients & $3.02(1.69-5.40)$ & NA & NA \\
\hline$/ \ln \_P$ & $0.0066(-0.1022-0.1035)$ & $0.5010(-0.0548-1.0569)$ & $-0.0121(-0.1167,0.09259)$ \\
\hline$P$ & 1.0007 (0.9028-I.I09I) & $1.6505(0.9467-2.8775)$ & $0.9880(0.8898-1.0970)$ \\
\hline \multirow[t]{3}{*}{$1 / p$} & $0.9989(0.9016-1.108)$ & $0.6105(0.3475-1.0056)$ & $1.0121(0.9116-1.1238)$ \\
\hline & $\operatorname{LR} \chi^{2}(12)=|2| .36$ & $\operatorname{LR} \chi^{2}(12)=|8.9|$ & $\operatorname{LR} \chi^{2}(12)=93.30$ \\
\hline & Prob $>\chi^{2}=0.0000$ & Prob $>\chi^{2}=0.0415$ & Prob $>\chi^{2}=0.0000$ \\
\hline
\end{tabular}

Abbreviations: $\mathrm{CCl}$, Charlson Comorbidity Index; LR $\left(\chi^{2}\right)$, likelihood ratio chi-square; Prob, probability; NA, not applicable. 


\section{Risk factors to discontinue biologics}

Compared to existing Japanese studies, our findings confirmed that elderly patients tend to have a higher persistence rate than younger aged patients..$^{24,40}$ The regression results give rise to evidence (limited to the continuing population) that comorbidities increased the probability of treatment discontinuation, which is in line with international results. ${ }^{21}$ Other studies, however, found that the CCI does not affect persistence, ${ }^{9,25}$ and the indication of peptic ulcer disease even had a positive effect on persistence of tumor necrosis factor inhibitors. ${ }^{25}$ According to our estimates, the elderly seem to be more persistent than younger patients. That elderly patients are more persistent is a well-established result both in $\mathrm{RA}^{8,40}$ and many other indications. ${ }^{31}$ With regard to adherence, which is a related but different concept, previous studies suggested a lower adherence among older patients. ${ }^{41}$ Both adherence and persistence were reported to be related to treatment satisfaction, ${ }^{42}$ which underlines the relevance of defining persistence as a treatment goal in RA.

\section{Limitations}

Several limitations should be discussed. One limitation of this study was that claims data analysis in general can utilize only a very limited set of medical parameters. Therefore, we could not control for RA-specific disease severity and disease activity at the time of biologic treatment initiation. Second, we could not determine the reasons for treatment discontinuation. This could be due to adverse events, lack of efficacy, or even clinical remission. Last, generalizability of these findings should be interpreted with caution. As our data were generated in large Japanese DPC hospitals, we cannot rule out the possibility of a bias toward patients whose RA was more severe than that of the general patient population. The results are therefore not necessarily representative of the daily practice of RA treatment in Japan. We were unable to include economic variables, such as out-of-pocket expenditures, into the analysis. In the Japanese universal health insurance system, all biologics are reimbursed but are subject to significant copayments of $30 \%$ for patients below 70 years and $10 \%$ for pensioners over 70 years of age. Absolute copayments are capped depending on the household's income. Therefore, individual out-of-pocket payments are highly variable among the patients and might also contribute to the observed variability of persistence rates.

Future research should also include more patientspecific psychological determinants of persistence, such as professional or family member support. ${ }^{43}$ Long-term follow-up of persistence and adherence to RA treatment are also needed to ensure optimal disease management. This is especially true in cases of very high general persistence rates in Japan, which makes it difficult to differentiate between drug survival rates.

\section{Conclusion}

Based on administrative data in Japan, we found that persistence rates of biologic agents for the treatment of RA appeared to be higher than in Western countries. Age and comorbidities influenced persistence rates. Although general persistence rates were high, there was a considerable and significant variation between different biologics and other factors, such as age, comorbidities, and patient type.

\section{Acknowledgments}

JM and RS received no specific funding for this work. Because we used commercially available hospital claims data from Medical Data Vision Co., Ltd., the dataset supporting the conclusions is not publicly available.

\section{Author contributions}

JM and RS made substantial contributions to conception and design, or acquisition of data, or analysis and interpretation of data; JM was involved in drafting the manuscript; JM and RS discussed the critical important intellectual content and revised the manuscript accordingly; and JM gave final approval of the version to be published.

\section{Disclosure}

JM and RS are employed at Janssen pharmaceutical KK. The authors report no other conflicts of interest in this work.

\section{References}

1. Yamanaka H, Sugiyama N, Inoue E, Taniguchi A, Momohara S. Estimates of the prevalence of and current treatment practices for rheumatoid arthritis in Japan using reimbursement data from health insurance societies and the IORRA cohort (I). Mod Rheumatol. 2014;24(1):33-40.

2. Smolen JS, Landewé R, Breedveld FC, et al. EULAR recommendations for the management of rheumatoid arthritis with synthetic and biological disease-modifying antirheumatic drugs. Ann Rheum Dis. 2010; 69(6):964-975.

3. Curtis JR, Singh JA. The use of biologics in rheumatoid arthritis: current and emerging paradigms of care. Clin Ther. 2001;33(6):679-707.

4. Listing J, Kekow J, Manger B, et al. Mortality in rheumatoid arthritis: the impact of disease activity, treatment with glucocorticoids, TNFo inhibitors and rituximab. Ann Rheum Dis. 2015;74(2):415-421.

5. Cramer J, Roy A, Burrell A, et al. Medication compliance and persistence: terminology and definitions. Value Health. 2008;11(1):44-47.

6. Blum MA, Koo D, Doshi JA. Measurement and rates of persistence with and adherence to biologics for rheumatoid arthritis: a systematic review. Clin Ther. 2011;33(7):901-913.

7. Lyu R, Govoni M, Ding Q, et al. Treatment persistence among patients with rheumatoid disease (RA, AS, PsA) treated with subcutaneous biologics in Germany. Rheumatol Int. 2016;36(1):143-153. 
8. Zink A, Listing J, Kary S, et al. Treatment continuation in patients receiving biological agents or conventional DMARD therapy. Ann Rheum Dis. 2005;64(9):1274-1279.

9. Neubauer S, Cifaldi M, MittendorfT, Ganguli A, Wolff M, Zeidler J. Biologic TNF inhibiting agents for treatment of rheumatoid arthritis: persistence and dosing patterns in Germany. Health Econ Rev. 2014;4(1):32.

10. Carmona L, Gomez-Reino JJ; BIOBADASER Group. Survival of TNF antagonists in spondylarthritis is better than in rheumatoid arthritis. Data from the Spanish registry BIOBADASER. Arthritis Res Ther. 2006;8(3):R72.

11. Kievit W, Fransen J, Adang EM, et al. Long-term effectiveness and safety of TNF-blocking agents in daily clinical practice: results from the Dutch rheumatoid arthritis monitoring register. Rheumatology. 2011;50(1): 196-203.

12. Markatseli TE, Alamanos Y, Saougou I, Voulgari PV, Drosos AA. Survival of TNF-alpha antagonists in rheumatoid arthritis: a long-term study. Clin Exp Rheumatol. 2012;30(1):31-38.

13. Jobanputra P, Maggs F, Deeming A, et al. A randomised efficacy and discontinuation study of etanercept versus adalimumab (RED SEA) for rheumatoid arthritis: a pragmatic, unblinded, non-inferiority study of first TNF inhibitor use: outcomes over 2 years. BMJ Open. 2012;2(6):e001395.

14. Svedborn A, Dalen J, Lyu R, et al. Treatment persistence among patients with rheumatoid disease (RD) newly treated with subcutaneous TNF alpha blockers. Ann Rheum Dis. 2015;74:330.

15. Sangiorgi D, Benucci M, Nappi C, Perrone V, Buda S, Degli Esposti L. Drug usage analysis and health care resources consumption in naïve patients with rheumatoid arthritis. Biologics. 2015;9:119-127.

16. Du Pan SM, Dehler S, Ciurea A, Ziswiler HR, Gabay C, Finckh A; Swiss Clinical Quality Management Physicians. Comparison of drug retention rates and causes of drug discontinuation between anti-tumor necrosis factor agents in rheumatoid arthritis. Arthritis Rheum. 2009;61(5):560-568.

17. Fisher A, Bassett K, Wright JM, Brookhart MA, Freeman H, Dormuth CR. Comparative persistence of the TNF antagonists in rheumatoid arthritis a population-based cohort study. PLoS One. 2014;9(8):e105193.

18. Johnston S, McMorrow D, Farr A, Juneau P, Ogale S. Comparison of biologic disease-modifying antirheumatic drug therapy persistence between biologics among rheumatoid arthritis patients switching from another biologic. Rheum Ther. 2015;2(1):59-71.

19. Tang B, Rahman M, Waters HC, Callegari P. Treatment persistence with adalimumab, etanercept, or infliximab in combination with methotrexate and the effects on health care costs in patients with rheumatoid arthritis. Clin Ther. 2008;30(7):1375-1384.

20. Borah B, Huang X, Zarotsky V, Globe D. Trends in RA patients' adherence to subcutaneous anti-TNF therapies and costs. Curr Med Res Opin. 2009;25(6):1365-1377.

21. Agarwal S, Glass R, Shadick N, et al. Predictors of discontinuation of tumor necrosis factor inhibitors in patients with rheumatoid arthritis. J Rheumatol. 2008;35(9):1737-1744.

22. Ramiro S, Landewé R, van der Heijde D, Harrison D, Collier D, Michaud K. Discontinuation rates of biologics in patients with rheumatoid arthritis: are TNF inhibitors different from non TNF inhibitors? RMD Open. 2015;1(1):e000155.

23. Baser O, Ganguli A, Roy S, Xie L, Cifaldi M. Impact of switching from an initial tumor necrosis factor inhibitor on health care resource utilization and costs among patients with rheumatoid arthritis. Clin Ther. 2015;37(7):1454-1465.

24. Cho SK, Sung YK, Choi CB, Bae SC. Impact of comorbidities on TNF inhibitor persistence in rheumatoid arthritis patients: an analysis of Korean national health insurance claims data. Rheumatol Int. 2012; 32(12):3851-3856.

25. Kang JH, Park DJ, Lee JW, et al. Drug survival rates of tumor necrosis factor inhibitors in patients with rheumatoid arthritis and ankylosing spondylitis. J Korean Med Sci. 2014;29(9):1205-1211.
26. Sakai R, Tanaka M, Nanki T, et al. Drug retention rates and relevant risk factors for drug discontinuation due to adverse events in rheumatoid arthritis patients receiving anticytokine therapy with different target molecules. Ann Rheum Dis. 2012;71(11):1820-1826.

27. Saokaew S, Sugimoto T, Kamae I, Pratoomsoot C, Chaiyakunapruk N. Healthcare databases in Thailand and Japan: potential sources for health technology assessment research. PLoS One. 2015;10(11): e0141993.

28. Wang K, Li P, Chen L, Kato K, Kobayashi M, Yamauchi K. Impact of the Japanese diagnosis procedure combination-based payment system in Japan. J Med Syst. 2010;34(1):95-100.

29. Quan H, Sundararajan V, Halfon P, et al. Coding algorithms for defining comorbidities in ICD-9-CM and ICD-10 administrative data. Med Care. 2005;43(11):1130-1139.

30. Wu E, Chen L, Birnbaum H, Yang E, Cifaldi M. Retrospective claims data analysis of dosage adjustment patterns of TNF antagonists among patients with rheumatoid arthritis. Curr Med Res Opin. 2008; 24(8):2229-2240.

31. Yeaw J, Benner JS, Walt JG, Sian S, Smith DB. Comparing adherence and persistence across 6 chronic medication classes. J Manag Care Pharm. 2009;15(9):728-740.

32. Singh JA, Saag KG, Bridges SL Jr, et al. 2015 American College of Rheumatology Guideline for the treatment of rheumatoid arthritis. Arthritis Rheumatol. 2016;68(1):1-26.

33. Lee P, Walt J, Chiang T, Guckian A, Keener J. A gap analysis approach to assess patient persistence with glaucoma medication. Am J Ophthalmol. 2007;144(4):520-524.

34. Ogale S, Hitraya E, Henk H. Patterns of biologic agent utilization among patients with rheumatoid arthritis: a retrospective cohort study. BMC Musculoskelet Disord. 2011;12:204.

35. Tanaka Y, Takeuchi T, Inoue E, et al. Retrospective clinical study on the notable efficacy and related factors of infliximab therapy in a rheumatoid arthritis management group in Japan: one-year clinical outcomes (RECONFIRM-2). Mod Rheumatol. 2008;18(2):146-152.

36. Koike T, Harigai M, Inokuma S, et al. Postmarketing surveillance of the safety and effectiveness of etanercept in Japan. J Rheumatol. 2009; 36(5):898-906.

37. Fewtrell M, Kennedy K, Singhal A, et al. How much loss to follow-up is acceptable in long-term randomised trials and prospective studies? Arch Dis Child. 2008;93:458-461.

38. Petri H, Urquhart J. Channeling bias in the interpretation of drug effects. Stat Med. 1991;10(4):577-581.

39. Chia LR, Schlenk EA, Dunbar-Jacob J. Effect of personal and cultural beliefs on medication adherence in the elderly. Drugs Aging. 2006; 23(3):191-202.

40. Matsubara H, Kojima T, Kaneko A, et al. Long-term retention rate and risk factor for discontinuation due to insufficient efficacy and adverse events in Japanese patients with rheumatoid arthritis receiving etanercept therapy. J Rheumatol. 2014;41(8):1583-1589.

41. Salaffi F, Carotti M, Di Carlo M, Farah S, Gutierrez M. Adherence to anti-tumor necrosis factor therapy administered subcutaneously and associated factors in patients with rheumatoid arthritis. J Clin Rheumatol. 2015;21(8):419-425.

42. Barbosa CD, Balp MM, Kulich K, Germain N, Rofail D. A literature review to explore the link between treatment satisfaction and adherence, compliance, and persistence. Patient Prefer Adherence. 2012;6:39-48.

43. Morgan C, McBeth J, Cordingley L, et al. The influence of behavioural and psychological factors on medication adherence over time in rheumatoid arthritis patients: a study in the biologics era. Rheumatology (Oxford). 2015;54(10):1780-1791. 
Patient Preference and Adherence

Dovepress

\section{Publish your work in this journal}

Patient Preference and Adherence is an international, peer-reviewed, open access journal that focuses on the growing importance of patient preference and adherence throughout the therapeutic continuum. Patient satisfaction, acceptability, quality of life, compliance, persistence and their role in developing new therapeutic modalities and compounds to optimize

Submit your manuscript here: http://www.dovepress.com/patient-preference-and-adherence-journ clinical outcomes for existing disease states are major areas of interest for the journal. This journal has been accepted for indexing on PubMed Central. The manuscript management system is completely online and includes a very quick and fair peer-review system, which is all easy to use. Visit http://www. dovepress.com/testimonials.php to read real quotes from published authors. 